\title{
The cleaning efficiency of the root canal after different instrumentation technique and irrigation protocol: A SEM analysis
}

\author{
Ferit Koçani $^{1}$, Blerim Kamberi ${ }^{1}$, Edmond Dragusha ${ }^{1}$, Shefqet Mrasori ${ }^{1}$, Fehim Haliti ${ }^{2}$ \\ ${ }^{1}$ Dental Pathology and Endodontics, Faculty of Medicine/Stomatology, University of Prishtina, Prishtina, Kosovo \\ ${ }^{2}$ Pediatric Dentistry, Faculty of Medicine/Stomatology, University of Prishtina, Prishtina, Kosovo \\ Email: ferit.kocani@uni-pr.edu
}

Received 11 April 2012; revised 2 May 2012; accepted 21 May 2012

\begin{abstract}
Aim: The objective of this study was to evaluate the effectiveness of manual and ultrasonic instrumentation with varying irrigation protocols on removal of the smear layer from root canal walls. Methods: Forty extracted single rooted human teeth stored in $0.5 \%$ saline were used. Periodontal soft tissues were removed followed by crown separation at the CEJ. All the teeth were randomly divided into two groups. Manually Instrumented Group 1 was irrigated with $5.25 \% \mathrm{NaOCl}$ and $17 \%$ EDTA alternately, same as Ultrasonically Instrumented Group 2. The controls for both groups were irrigated with saline solution. Results: Ultrasonic instrumentation and the combined use of two different solutions $(5.25 \% \mathrm{NaOCl}$ and $17 \%$ EDTA) yielded better results on smear removal. Conclusions: Irrigation with $17 \%$ EDTA followed by $5.25 \% \mathrm{NaOCl}$ was successful in complete removal of smear layer on cervical and middle thirds of the root canals. Ultrasonic instrumentation was slightly more successful on the apical one third of the root canals.
\end{abstract}

Keywords: Smear Layer; Instrumentation; Manual; Ultrasonic; Cleaning; Irrigation

\section{INTRODUCTION}

An accepted axiom in endodontic treatment is that the root canal must be cleaned, shaped and obturated as well as possible.

Complete removal of pulpal tissue (if possible at all), is difficult. Pulpal tissue remnants will persist closely connected to dentine walls even with current cleaning and shaping techniques. In addition, the inner configuration of the root canal system and the pulpal space are highly complex [1]. There are lateral and accessory canals that make root canal treatment (RCT) even more difficult. Hence the need for appropriate instruments and irrigants for chemo mechanical instrumentation of the root canal system(s).

Root canal instrumentation enables the removal of the pulpal tissues, both inflamed and necrotic, including a thin layer of intracanal dentin. Consequently, some changes on the inner dentin walls of the root canal occur, yielding a layer named as "the smear layer" [2], which is $1 \mu \mathrm{m}$ thick at the surface [3]. However, this layer is not present on intact root canal walls. The cutting debris is forced at variable depths into dentin tubules creating these so-called smear plugs [4]. The superficial smear layer is loosely attached to the root canal wall [5]. The biochemical composition of the smear layer is not fully understood. One assumption is that this layer contains inorganic particles of dental hard tissues and organic components from pulp tissues, i.e. odontoblasts, micro organisms and blood cells.

Recent research demonstrates that the success of smear layer removal depends on the instrumentation techniques and irrigation solutions [6-9]. Sodium hypochlorite solution $(\mathrm{NaOCl})$ has been the commonly used irrigant for over four decades, especially for its effective antibacterial and excellent organic material dissolving properties [10-12]. On the other hand, sodium hypochlorite is considered toxic to the periapical tissues (if extruded), especially when high concentrations are used $[13,14]$. The use of a single irrigant was not sufficient to remove the smear layer; therefore $15 \%-17 \%$ ethylenediaminetetraacetic acid (EDTA) solution at $\mathrm{pH} 7-8$ was introduced for chelating calcium in dentine [15-20]. The cationic surfactant cetyltrimethylammonium bromide provided lower surface tension and added bacteriostatic action to the EDTA solution [21].

Currently, there are a number of techniques available for root canal instrumentation. Ultrasonic and manual instrumentation in combination with various irrigating solutions enhance smear layer removal [22-25]. Ciucchi 
et al. [26] reported that ultrasonics combined with $3 \%$ $\mathrm{NaOCl}$ failed to completely remove the smear layer and did not enhance the chelating capability of EDTA. They also observed a decreased efficiency of the irrigation solutions toward the apical third of root canals. Moreover, Abbott et al. [27] reported that $\mathrm{NaOCl}$ in combination with EDTAC produced clean canal walls and ultrasonics did not enhance the cleaning action of the respective solutions.

Cunningham and Martin [22,28] in their scanning electron microscope (SEM) study evaluated manual and ultrasonic instrumentation techniques combined with $2.5 \% \mathrm{NaOCl}$ for irrigation. They concluded that manual instrumentation created a coarse smear layer contrary to ultrasonic instrumentation. Ahmad et al. [29] in his comparative study between manual and ultrasonic instrumentation techniques showed a quantitative difference between the two. In fact, manual instrumentation and irrigation with $2.5 \% \mathrm{NaOCl}$ created less smear, with varying thickness and in some parts of root canal walls was completely missing. He concluded that the cleaning of the root canal space is more dependent on the type of irrigation, than on the method of instrumentation.

Brannstrom et al. [30] provided data on the effectiveness of sonic and ultrasonic preparation of the root canals including the advantages of manual instrumentation of the root canal system. Ultrasonics in combination with various irrigants promotes smear layer removal. Comparison of the efficacy of "F-File" with passive sonic and ultrasonic irrigation on removal of artificially placed debris from simulated uninstrumented root canals showed that passive ultrasonic instrumentation combined with syringe irrigation with $1 \% \mathrm{NaOCl}$ were capable of removing significantly more debris than the other two methods [31]. Yamashita et al. [32] performed a SEM analysis evaluating the cleanliness of the root canal systems following their irrigation with $2 \%$ chlorhexidine, $2.5 \% \mathrm{NaOCl}$ and a combination of $2.5 \% \mathrm{NaOCl}$ and EDTA. The results showed that the latter irrigation protocol was superior at the coronal and middle thirds of the root canals. They conclusively report the inferiority of all chemo mechanical techniques in achieving complete smear layer removal at the apical thirds of the root canal systems.

The objective of this study was to evaluate the effectiveness of manual and ultrasonic instrumentation with varying irrigation protocols on removal of the smear layer from root canal walls.

\section{MATERIAL AND METHODS}

Forty freshly extracted single rooted human teeth $(n=40)$ stored in $0.5 \%$ saline were used as a study material. They were mainly upper incisors and mandibular premolars (with a single canal), which were extracted for their poor periodontal prognosis and orthodontic indications. The periodontal soft tissues were removed followed by crown separation at the cement-enamel junction (CEJ) using high-speed fissure burs (Bien-Air, Bienne, Switzerland) under water spray. According to the instrumentation technique all the teeth were randomly divided into two major groups with 20 teeth each (Table 1). Group 1Manual Instrumentation and Group II-Ultrasonic Instrumentation. Both groups had a Control Group irrigated with saline and were divided into subgroups according to the irrigation protocols that were varied. Both groups were divided into subgroups, according to following irrigation protocols: Group I.1. Irrigated with saline (Control Group), I.2. Irrigated with $5.25 \% \mathrm{NaOCl}$ (ADD Vision, Germany), I.3. Irrigated with 17\% EDTA (Calcinase, LegeArtis Pharma Dettenhausen, Germany) and I.4. Irrigated with a combination of $17 \%$ EDTA and $5.25 \% \mathrm{NaOCl}$ solutions. Group II.1. Irrigated with saline (Control Group), II.2. Irrigated with 5.25\% NaOCl, II.3. Irrigated with $17 \%$ EDTA and II.4. Irrigated with $17 \%$ EDTA and $5.25 \% \mathrm{NaOCl}$ solutions.

Pulp tissue was removed using barbed broaches (DENTSPLY, Tulsa, USA). Manual instrumentation (Group I) of the root canal systems was performed with K-type Flex files (Kerr Mfg. Co., Romulus, Michigan, USA). Working lengths were established at $0.5 \mathrm{~mm}$ short of the anatomical apex by visually identifying \#10 K-file at the apical foramina. The roots were instrumented to \#45 K-file using the step-back preparation technique and irrigated with $2.0 \mathrm{ml}$ of irrigant at each change of instrument. The canals were irrigated with EDTA for 20 $30 \mathrm{sec}$. and sodium hypochlorite for 1 minute.

Ultrasonic instrumentation (Group II) was performed with Enac-3 EM-OSADA (Enac-3 EM-OSADA, Tokyo, Japan), at a frequency of over $20.000 \mathrm{~Hz}$, powered by a standard electrical power. The power adjustment of the unit was set at level 3. Initial canal scouting was performed with \#8 or \#10 K-files.

Table 1. Distribution of samples depending on instrumentation technique and irrigation protocol.

\begin{tabular}{ll}
\hline \multicolumn{1}{c}{ Group I } & \multicolumn{1}{c}{ Group II } \\
$\begin{array}{l}\text { (Manual instrumentation with } \\
\text { K-type Flex files) } \\
\text { Irrigation Protocol }\end{array}$ & $\begin{array}{l}\text { (Ultrasonic instrumentation with } \\
\text { Enac-3 EM-OSADA) } \\
\text { Irrigation Protocol }\end{array}$ \\
\hline $\begin{array}{l}\text { I.1. Saline sol. (Control Group) } \\
\text { II.1.Saline sol. (Control Group) }\end{array}$ & II.2. 5.25\% NaOCl \\
I.2. 5.25\% NaOCl $17 \%$ EDTA & II.3. 17\% EDTA \\
$\begin{array}{l}\text { I.4. Combination of 5.25\% } \\
\text { NaOCl and 17\% EDTA }\end{array}$ & $\begin{array}{l}\text { II.4. Combination of 5.25\% } \\
\text { NaOCl and 17\% EDTA }\end{array}$ \\
\hline
\end{tabular}


The ultrasonic file mounted on the hand piece, was placed in the canal to the measured length. Upon activation the file was moved passively in up-down motion to ensure it did not bind to the root canal walls. The canals were instrumented with \#15 through \#45 hand files. After shaping the canal a small ultrasonic clearing file was introduced to the apex. Each consecutive energized ultrasonic file was used continuously with 17\% EDTA for 20 - 30 seconds and with sodium hypochlorite for 1 minute. Irrigation solutions were delivered via a $10 \mathrm{~mL}$ syringe, at a rate of $15 \mathrm{~mL}$ per canal. Group II.4. \& I.4. samples were irrigated with equal amounts of $17 \%$ EDTA and $5.25 \% \mathrm{NaOCl}$ alternately followed by a final irrigation with $2 \mathrm{~mL}$ of $5.25 \% \mathrm{NaOCl}$.

Irrigants were delivered via a 23 gauge needle $\left(\right.$ Romed $^{\circledR}$ Holland, CH Wilnis, NL) inserted into the canal without binding. Two milliliters of saline solution were used as a final irrigant to avoid long-term action of the tested irrigants. All teeth were dried with paper points (DENTSPLY, Maillefer, Switzerland) and split along the long axis in the bucco-lingual direction to expose the entire extent of the root canal.

The teeth were fixed in glutaraldehyde solution and air dried with hot air and left in an air tight environment.

The resulting specimens were prepared for Scanning Electron Microscope JEOL JSM-6335F (Tokyo, Japan). The teeth were cut with ISOMET 11-1180 low speed saw at the predetermined coronal, middle and the apical thirds. The cut samples were fixed in metallic blocks and put on the Sputter Coater S150 B EDWARDS for impregnation in gold $\mathrm{Au})$ at $10 \mathrm{mbar}$ pressure. Internal parts of the root canal systems were specially microfilmed. After scanning and observing each third with the microscope, an image of the most representative area a third was taken. Three pictures were obtained from each tooth, one for each third, to give a total of 120 pictures. The images were analyzed for the amount of smear layer, scored as: $1=$ no smear layer; $2=$ few areas covered by smear layer with many dentin tubule orifices visible; $3=$ most areas covered by smear layer, with few dentin tubule orifices visible; $4=$ all areas covered by smear layer, no dentin tubule orifices visible, $5=$ Heavy, non-homogeneous smear layer covering the complete root canal wall.

Statistical analysis using Friedman's test was used to find if there is any difference in the effectiveness of instrumentation technique on removal of smear layer.

\section{RESULTS}

The amount of the remaining smear layer in each third of a group was as follows:

Control Groups I.1 and II.1, showed no significant difference between the groups (Table 2), (Figure 1(a))
Table 2. Scores of smear layer within the group, irrigation with saline sol. (control group).

\begin{tabular}{ccccc}
\hline $\begin{array}{c}\text { Instrument } \\
\text { technique }\end{array}$ & $\begin{array}{c}\text { Third of the } \\
\text { root canal }\end{array}$ & $\begin{array}{c}\text { Mean } \\
\text { score }\end{array}$ & SD & P value \\
\hline Manual & cervical & 5.0 & 0.00 & $\mathrm{NT}^{*}$ \\
Ultrasonic & & 5.0 & 0.00 & \\
Manual & middle & 5.0 & 0.00 & $\mathrm{NT}^{*}$ \\
Ultrasonic & & 5.0 & 0.00 & \\
Manual & & 5.0 & 0.00 & $\mathrm{NT}^{*}$ \\
Ultrasonic & apical & 5.0 & 0.00 & \\
\hline
\end{tabular}

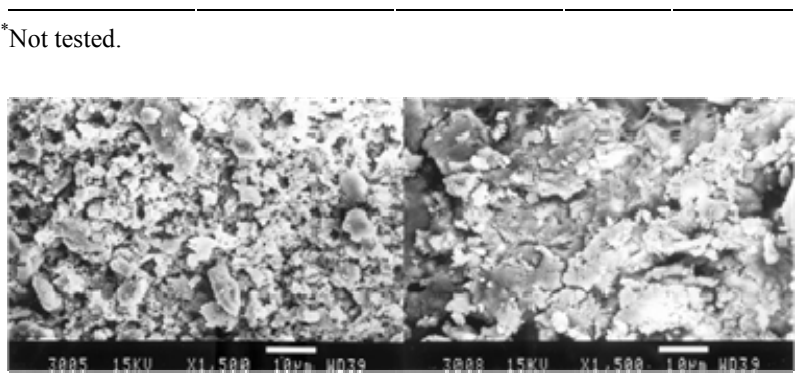

(a)

(b)

Figure 1. Manually instrumentation (a) and Ultrasonically (b) instrumentation, saline sol. irrigation, middle third, original magnification $\times 1500$.

with heterogeneous smear layer coating the root canal walls (Group I.1), that completely covered the instrumented areas (Group II.1) (Figure 1(b)). The smear layer also penetrated the dentin tubules.

In Groups I.2 and II.2 (5.25\% NaOCl), ultrasonic instrumentation was significantly more effective for the removal of the smear layer at cervical and middle thirds (score 1.6 vs 3.8), $(\mathrm{P}<0.05)$, (Table 3).

However, there was no statistical significance between the groups in the apical third. Group I.2, produced a smear layer that resembled dry, cracked soil surface, which covered dentin tubules (Figure 2(a)). Group II.2 specimens had smeared free areas throughout (Figure 2(b)).

Groups I.3 and II.3 (17\% EDTA.) had higher scores of smear layer found throughout their root canals (Table 4) with no statistical differences between ultrasonic and manual instrumentation (4.8 vs 5.0) $(\mathrm{P}>0.05)$.

Instrumented areas of the root canals in Group I.3, were covered with smear (Figure 3(a)). In Group II.3, the smear layer covered the dentin tubules and in few areas created dentinal plugs (Figure 3(b)).

Smear layer removal at the cervical and middle thirds in both major groups was more effective when irrigated with combined use of $5.25 \% \mathrm{NaOCl}$ and $17 \%$ EDTA (Groups I.4 and II.4) (Score 1 vs 1.4). In apical thirds of the roots, ultrasonic instrumentation was slightly more 
Table 3. Scores of smear layer within the group, irrigation with $\mathrm{NaOCl} 5,25 \%$.

\begin{tabular}{ccccc}
\hline $\begin{array}{c}\text { Instrument } \\
\text { technique }\end{array}$ & $\begin{array}{c}\text { Third of the } \\
\text { root canal }\end{array}$ & Mean score & SD & P value \\
\hline Manual & Cervical & 3.8 & 0.40 & $<0.001$ \\
Ultrasonic & & 1.6 & 0.55 & \\
\hline Manual & Middle & 4.2 & 0.45 & $<0.001$ \\
Ultrasonic & & 2.2 & 0.45 & \\
\hline Manual & Apical & 4.4 & 0.55 & 0.24 \\
Ultrasonic & & 4.8 & 0.45 & \\
\hline
\end{tabular}

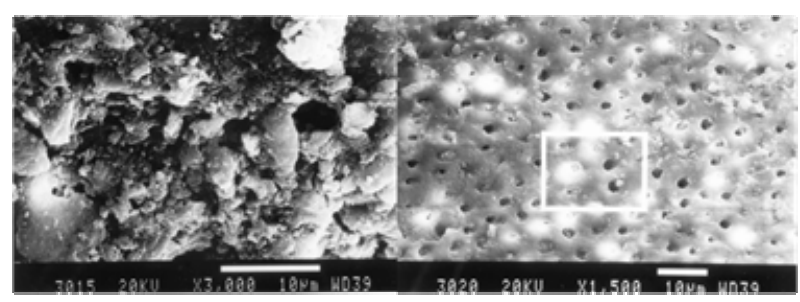

(a)

(b)

Figure 2. Manually instrumentation (a) and Ultrasonically instrumentation (b), irrigation with $5.25 \% \mathrm{NaOCl}$, middle third, original magnification (a) $\times 3000$ and (b) $\times 1500$.

Table 4. Scores of smear layer within the group, irrigation with $17 \%$ EDTA.

\begin{tabular}{ccccc}
\hline $\begin{array}{c}\text { Instrument } \\
\text { technique }\end{array}$ & $\begin{array}{c}\text { Third of the } \\
\text { root canal }\end{array}$ & $\begin{array}{c}\text { Mean } \\
\text { score }\end{array}$ & SD & P value \\
\hline $\begin{array}{c}\text { Manual } \\
\text { Ultrasonic }\end{array}$ & Cervical & 5 & 0.00 & 0.35 \\
\hline Manual & Middle & 5 & 0.00 & 0.35 \\
Ultrasonic & & 4.8 & 0.45 & \\
\hline Manual & Apical & 5 & 0.00 & $\mathrm{NT}^{*}$ \\
Ultrasonic & & 5 & 0.00 & \\
\hline
\end{tabular}

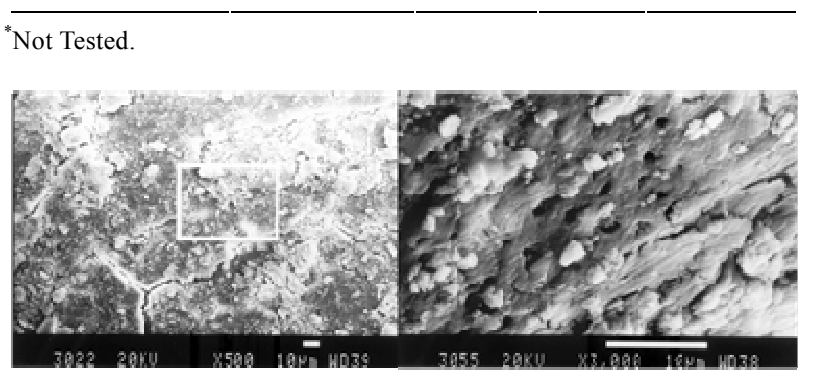

(a)

(b)

Figure 3. Manually instrumentation (a) and Ultrasonically instrumentation (b), irrigation with $17 \%$ EDTA, middle third, original magnification $(a) \times 500$ and $(b) \times 3000$.

effective (score 1.8 vs 2) (Table 5). No significant difference was found between the instrumentation techniques and irrigants used $(\mathrm{P}>0.05)$. In the apical third of the root canals in Group I.4, the orifices and the smear were clearly visible in some parts of dentin walls (Figure 4(a)). Furthermore, debris was also present in this view.

The middle third of the instrumented root canals yielded a slightly different picture, because here the dentin orifices were patent and the smear layer was completely removed. Debris was consistently present throughout. In Group II.4, the root canal walls and the orifices of the dentin tubules were patent with some visible debris (Figure 4(b)).

\section{DISCUSSION}

Cleaning and shaping of the root canal space are the objectives of root canal treatment. The success varies according to used techniques [5,30-33]. Discovery of the smear layer by Mc Comb and Smith [2] clarified the interaction between the root canal instruments and the inner dentinal walls. This active interaction provided researchers with new directions on methods to remove these residues. Our research shows that manual or ultrasonic instrumentation techniques with saline solution as a irrigant tend to form an amorphous mass which covers the entire dentinal wall of the treated canal, namely the smear layer. Smear also tends to pack deep into the tubules $[5-6,9,22,24]$. This occurrence is a direct effect of the action between root canal instruments and the

Table 5. Scores of smear layer within the group, irrigation with $\mathrm{NaOCl} 5.25 \%$ and EDTA.

\begin{tabular}{ccccc}
\hline $\begin{array}{c}\text { Instrument } \\
\text { Technique }\end{array}$ & $\begin{array}{c}\text { Third of the } \\
\text { root canal }\end{array}$ & $\begin{array}{c}\text { Mean } \\
\text { score }\end{array}$ & SD & P value \\
\hline Manual & Cervical & 1 & 0.00 & $\mathrm{NT}^{*}$ \\
Ultrasonic & & 1 & 0.00 & \\
Manual & Middle & 1.4 & 0.55 & $\mathrm{NT}^{*}$ \\
Ultrasonic & & 1.4 & 0.55 & \\
Manual & Apical & 2 & 0.71 & 0.7 \\
Ultrasonic & & 1.8 & 0.84 & \\
\hline
\end{tabular}

${ }^{*}$ Not tested.

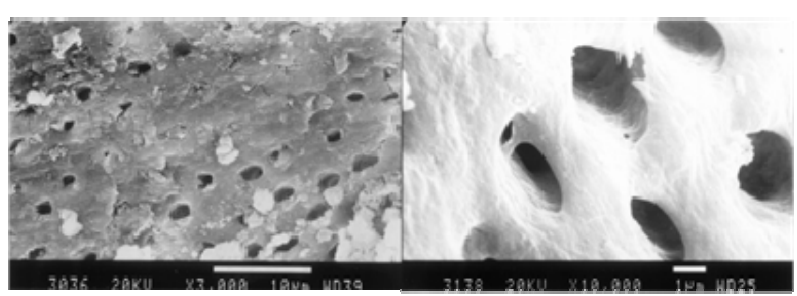

(a)

(b)

Figure 4. Manually instrumentation (a) and Ultrasonically instrumentation (b), irrigation with $17 \%$ EDTA followed by $5.25 \% \mathrm{NaOCl}$, middle third, original magnification (a) $\times 3000$ and (b) $\times 10,000$. 
dentinal walls [2,9,34]. With ultrasonic instrumentation the smear layer has a different appearance and it covers the whole treated wall [24,28,29,35].

The goal of irrigation is to remove pulp tissue and/or microorganism from the root canal system including the smear layer and dentine debris that are created when instrumenting root canals [36]. The efficacy of irrigation depends on the working mechanisms of the irrigant and the ability to bring the irrigant in close contact with those elements, materials and structures within the canal system, which have to be removed [18,37].

Ultrasonically activated files have the potential to mechanically prepare and debride root canals. Ultrasonic irrigation of the root canal can be performed with or without simultaneous ultrasonic instrumentation (passive instrumentation). The energy is transmitted by means of ultrasonic waves and can induce acoustic streaming and cavitation of the irrigant $[38,39]$. On this case the irrigant can penetrate more easily into the apical part of the root canal system and the cleaning effect will be more powerful [20]. Cesar de Gregorio et al. [40], have found that Sonic and Ultrasonic activation resulted in a better irrigation of the lateral canals at 4.5 and $2 \mathrm{~mm}$ from working length compared to traditional needle irrigation alone. Traditional needle irrigation alone demonstrated significantly less penetration of irrigant into the lateral canals and was limited to the level of penetration of the needle. Passive ultrasonic irrigation cause a rise in irrigant temperature in the main canal to $53.5^{\circ} \mathrm{C} \pm 2.7^{\circ} \mathrm{C}$ after the fifth minute, irrigation promotes positive tissuedissolving effects beyond a rise in irrigant temperature [41]. Irrigation with sodium hypochlorite increase tooth surface strain. The increase was significantly greater with $5 \% \mathrm{NaOCl}$ alone than with $5 \% \mathrm{NaOCl}$ alternated with $17 \%$ EDTA $[42,43]$.

Ultrasonic instrumentation and irrigation with $5.25 \%$ $\mathrm{NaOCl}$ was successful in removing the smear layer from the surface of the root canal inner wall but not entirely from the dentin tubules [23,26,34]. Berg et al. [35], Goldman et al. [3,7], and Baumgartner and Mader [44] obtained similar results when they compared the manual method with ultrasonic technique and irrigation with $5.25 \% \mathrm{NaOCl}$. Ahmad et al. [29], with ultrasonic instrumentation and irrigation with $5.25 \% \mathrm{NaOCl}$ managed to remove the smear layer from the surface of the root canal wall. They also noticed a considerate amount of debris, mainly in the curved canals. Cameron [24,25,34], using different concentrations of $\mathrm{NaOCl}$ noticed that: in cases when the concentration was higher than $2 \%$, the removal of the smear layer from the surface of the root canal wall was successful.

Many reports have demonstrated decalcifying capacity of EDTA at a concentration of $15 \%$ - $17 \%[17,45]$, citric acid at 5\% - 50\% [46,47], phosphoric acid at different concentration [45,48], 7\% maleic acid [49], and low concentration of paracetic acid [50] to remove the inorganic component from instrumented canal. The decalcifying efficacy of these acid and chelating agents depends on the root length, application time, diffusion in the dentine and solution $\mathrm{pH}[17,51]$. The use of a neutral $\mathrm{pH}$ of around 7.3 is recommended for EDTA solutions [17]. Collagen degradation significantly increase and the flexural strength of mineralized dentin significantly reduce after the use of $5.25 \% \mathrm{NaOCl}$ as the initial irrigant [52].

Research on the evaluation of manual and ultrasonic instrumentation techniques with combined irrigation with 17\% EDTA and 5.25\% NaOCl, demonstrated their effectiveness in complete removal of the smear layer from root canal walls and the orifice of dentin tubules on cervical and middle thirds [22-24,34]. In cases when $5.25 \% \mathrm{NaOCl}$ solution was used as a final irrigant, remnants of smear layer were occasionally visible.

Manual instrumentation and irrigation with EDTA solution, produces a large amount of smear layer. In ultrasonic instrumentation irrigated with EDTA, the smear layer of the root canal wall was partially removed on cervical and middle thirds, and smear layer was visibly packed in dentine tubules. These results demonstrate the effectiveness of EDTA and its demineralization potential $[7,15,35,53]$.

The association of EDTA and $\mathrm{NaOCl}$ solutions has proved effective in removing smear layer formed during endodontic instrumentation. EDTA cause decalcification upon the inorganic components of the smear layer and peri and intertubular dentine, and leaves the collagen exposed. Subsequently, the use of $\mathrm{NaOCl}$ dissolves the collagen, leaving the entrance to the dentinal tubules more open and exposed [17,18,37,38,54].

\section{CONCLUSIONS}

Based on our study, manual and ultrasonic instrumentation techniques and irrigation with saline solution produced a smear layer visible on the treated surfaces of the root canal walls.

Following manual instrumentation and irrigation with $17 \%$ EDTA and followed by $5.25 \% \mathrm{NaOCl}$, the smear layer was absent in the coronal and middle thirds of the root canal walls. Following ultrasonic instrumentation and irrigation with $5.25 \% \mathrm{NaOCl}$, the smear layer was removed from the surface of the root canal walls and from the orifice of dentin tubules. Ultrasonic instrumentation and irrigation with 17\% EDTA provide inner walls of root canals free of smear layer with occasional debris.

Ultrasonic and manual instrumentation, and irrigation with $17 \%$ EDTA followed by $5.25 \% \mathrm{NaOCl}$ was suc- 
cessful in complete removal of smear layer on cervical and middle thirds of the root canals, also ultrasonic instrumentation was slightly more effective on apical thirds of the root canals.

Ultrasonic instrumentation of the root canals and irrigation with combined irrigating solutions is effective in removal of the smear layer from the instrumented walls of the root canal systems.

\section{REFERENCES}

[1] Ricucci, D. and Langeland, K. (1988) Apical limit of root canal instrumentation and obturation, part 2: A histological study. International Endodontic Journal, 31, 394-409. doi:10.1046/j.1365-2591.1998.00183.x

[2] McComb, D. and Smith, C. (1975) A preliminary scanning electron microscopy study of root after endodontic procedures. Journal of Endodontics, 7, 238-242. doi:10.1016/S0099-2399(75)80226-3

[3] Goldman, L., Goldman, M. and Kronman, J. (1981) The efficacy of several irrigating solutions for endodontics: A scanning electron microscopic study. Oral Surgery, Oral Medicine, Oral Pathology, 2, 197-204. doi:10.1016/0030-4220(81)90319-4

[4] Mader, C., Baumgartner, J. and Peters, D. (1984) Scanning electron microscopic investigation of the smeared layer on root canal walls. Journal of Endodontics, 10, 477-483. doi:10.1016/S0099-2399(84)80204-6

[5] Lester, K. and Boyde, A. (1977) Scanning electron microscopy of instrumented, irrigated and filled root canals. British Dental Journal, 11, 359-367. doi:10.1038/sj.bdj.4804007

[6] Koskinen, K., Meurman, J. and Stenval, H. (1980) Appearance of chemically treated root canal walls in the scanning electron microscope. Scandinavian Journal of Dental Research, 88, 397-405.

[7] Goldman, M., Goldman, B.L., Cavaleri, R., Bogis, J. and Pec, S.L. (1982) The efficacy of several irrigating solutions for endodontics: A scanning electron microscopic study, part II. Journal of Endodontics, 11, 487-492. doi:10.1016/S0099-2399(82)80073-3

[8] Yamada, R.S., Annabelle, A., Goldman, M. and Peck, S.L. (1983) A scanning electron microscopic comparison of a high volume final flush with several irrigating solutions: Part III. Journal of Endodontics, 4, 137-142. doi:10.1016/S0099-2399(83)80032-6

[9] Sen, B., Wesselink, P. and Turkun, M. (1995) The smear layer: A phenomenon in root canal therapy. International Endodontic Journal, 3, 141-148. doi:10.1111/j.1365-2591.1995.tb00289.x

[10] Moorer, W. and Wesselink, P. (1982) Factors promoting the tissue dissolving capability of sodium hypochlorite. International Endodontic Journal, 4, 187-196.

[11] Cohen, S. and Burns, R. (1998) Pathways of the Pulp. 7th Edition, Mosby, St. Louis.

[12] Siqueira, J.F., Isabela N. R., Favieri, A. and Lima, K.C. (2000) Chemomechanical reduction of the bacterial population in the root canal after instrumentation and irrigation with $1 \%, 2.5 \%$, and $5.25 \%$ Sodium Hypochlorite. Journal of Endodontics, 26, 331-334. doi:10.1097/00004770-200006000-00006

[13] Ferraz, C., Gomes, B., Zaia, A.A., Teixeira, F.B. and De Souza-Filho, F. J. (2001) In vitro assessment of the antimicrobial action and the mechanical ability of the chlorhexidine gel as an endodontic irrigant. Journal of Endodontics, 7, 452-455. doi:10.1097/00004770-200107000-00004

[14] Kuruvilla, J. and Kamath, M. (1998) Antimicrobial activeity of $2.5 \%$ sodium hypochlorite and $0.2 \%$ chlorhexidine gluconate separately and combined, as irrigants. Journal of Endodontics, 7, 472-476. doi:10.1016/S0099-2399(98)80049-6

[15] Ostby, N. (1957) Chelation in root canal therapy. Odontologisk Tidskrift, 65, 3-11.

[16] O'Connell, M.S., Morgan, W. J. and Baumgartner, J.C. (2000) A comparative study of smear layer removal using different salts of EDTA. Journal of Endodontics, 26, 739743. doi:10.1097/00004770-200012000-00019

[17] Serper, A. and Çalt, S. (2002) The demineralizing effects of EDTA at different concentrations and $\mathrm{pH}$. Journal of Endodontics, 28, 501-502. doi:10.1097/00004770-200207000-00002

[18] Hülsmann, M., Heckendorff, M. and Lennon, A. (2003) Chelating agents in root canal treatment: Mode of action and indications for their use. International Endodontic Journal, 36, 810-830. doi:10.1111/j.1365-2591.2003.00754.x

[19] Khedmat, S. and Shokouhinejad, N. (2008) Comparison of the efficacy of three chelating agents in smear layer removal. Journal of Endodontics, 34, 599-602. doi:10.1016/j.joen.2008.02.023

[20] Spanó, J.C.E., Guedes, D.F.C., Sousa-Neto, M.D., Estrela, C. and Pécora, J. D. (2009) Atomic absorption spectrometry and scanning electron microscopy evaluation of concentration of calcium ions and smear layer removal with root canal chelators. Journal of Endodontics, 35, 727-730. doi:10.1016/j.joen.2009.02.008

[21] Hill, P. (1959) Endodontics. Journal of Prosthetic Dentistry, 9, 142.

[22] Martin, H., Cunningham, T. and Cotton, W. (1980) U1trasonic versus hand filing of dentine: A quantitative study. Oral Surgery, Oral Medicine, Oral Pathology, 1, 79-81. doi:10.1016/0030-4220(80)90034-1

[23] Cheung, G. and Stock, C. (1993) In vitro cleaning ability of root canal irrigants with and without endosonics. International Endodontic Journal, 6, 334-343. doi:10.1111/j.1365-2591.1993.tb00766.x

[24] Cameron, J. (1995) The choice of irrigant during hand instrumentation and ultrasonic irrigation of the root canal: A scanning electron microscope study. Australian Dental Journal, 2, 85-90. doi:10.1111/j.1834-7819.1995.tb03121.x

[25] Cameron, J. (1983) The use of ultrasonic in the removal of the smear layer: A scanning electron microscope study. Journal of Endodontics, 9, 289-292. 
doi:10.1016/S0099-2399(83)80119-8

[26] Ciucchi, B., Khettabi, M. and Holz, J. (1989) The effecttiveness of different endodontic irrigation procedures on the removal of the smear layer: A scanning electron microscopic study. International Endodontic Journal, 1, 2128. doi:10.1111/j.1365-2591.1989.tb00501.x

[27] Abbott, P.V., Heijkoop, P.S., Cardaci, S.C., Hume, W.R. and Heithersay, G.S. (1991) An SEM study of the effects of different irrigation sequences and ultrasonics. International Endodontic Journal, 6, 308-316. doi:10.1111/j.1365-2591.1991.tb00141.x

[28] Cunningham, V., Martin, H., Pelleu, G.B. and Stoops, D.E. (1982) Evaluation of root canal debridement by the endosonic ultrasonic synergistic system. Oral Surgery, Oral Medicine and Oral Pathology, 53, 401-404. doi:10.1016/S0099-2399(87)80173-5

[29] Ahmad, M., Pit, F.T. and Crum, L. (1987) Ultrasonic debridement of root canals: An insight into the mechanism involved. Journal of Endodontics, 3, 93-101.

[30] Brännström, M. (1990) Removal of the dentinal smear layer. Quintessence International, 21, 425-526.

[31] Gaurav, G. and Sangeeta, T. (2010) Comparison of the efficacy of "F-File" with sonic and ultrasonic debridement to remove artificially placed dentine debris from human root canals-An in vitro study. A Publication of Indian Endodontic Society, 22, 39-47.

[32] Yamashita, J., Filho, T.M., Leonardo, M.R., Rossi, M.A. and Silva, L.A.B. (2003) Scanning electron microscopic study of the cleaning ability of chlorhexidine as a rootcanal irrigant. International Endodontic Journal, 6, 391394. doi:10.1046/j.1365-2591.2003.00656.x

[33] McComb, D., Smith, D. and Beagrie, G. (1976) The results of in vivo endodontic chemo mechanical instrumenttation-A scanning electron microscopic study. Journal of British Endododontic Society, 9, 11-18.

[34] Cameron, J. (1995) Factors affecting the clinical efficiency of ultrasonic endodontics - A scanning electron microscopy study. International Endodontic Journal, 1, 47-53. doi:10.1111/j.1365-2591.1995.tb00156.x

[35] Berg, M., Jacobsen, E., BeGole, E. and Remeikis, N. (1986) A comparison of five irrigant solutions: A scanning electron microscopic study. Journal of Endodontics, 12, 192-197. doi:10.1016/S0099-2399(86)80153-4

[36] Haapasalo, M., Endal, U., Zandi, H. and Coil, J. (2005) Eradication of endodontic infection by instrumentation and irrigation solutions. Endodontic Topics, 10, 77-102. doi:10.1111/j.1601-1546.2005.00135.x

[37] Teixeira, C.S., Felippe, M. and Felippe, W. (2005) The effect of application time of EDTA and $\mathrm{NaOCl}$ on intracanal smear layer removal: An SEM analysis. International Endodontic Journal, 38, 285-290. doi:10.1111/j.1365-2591.2005.00930.x

[38] Ahmad, M., Pitt Ford, T. and Crum, L. (1987) Ultrasonic debridement of root canals: An insight into the mechanisms involved. Journal of Endodontics, 13, 93-101. doi:10.1016/S0099-2399(87)80173-5

[39] Ahmad, M., Pitt Ford, T., Crum, T. and Walton, A. (1988)
Ultrasonic debridement of root canals: Acoustic cavitation and its relevance. Journal of Endodontics, 14, 486493. doi:10.1016/S0099-2399(88)80105-5

[40] De Gregorio, C., Estevez, R., Cisneros, R. and Heilborn, C. (2009) Effect of EDTA, sonic, and ultrasonic activetion on the penetration of sodium hypochlorite into simulated lateral canals: An in vitro study. Journal of Endodontics, 35, 891-895. doi:10.1016/j.joen.2009.03.015

[41] Al-Jadaa, A., Paqué, F., Attin, T. and Zehnderet, M. (2009) Necrotic pulp tissue dissolution by passive ultrasonic irrigation in simulated accessory canals: Impact of canal location and angulation. International Endodontic Journal, 42, 59-65. doi:10.1111/j.1365-2591.2008.01497.x

[42] Rajasingham, R., Ng, Y. L., Knowles, J.C. and Gulabivala, K. (2010) The effect of sodium hypochlorite and ethylenediaminetetraacetic acid irrigation, individually and in alternation, on tooth surface strain. International Endodontic Journal, 43, 31-40. doi:10.1111/j.1365-2591.2009.01625.x

[43] Sobhani, O.E., Gulabivala, K.J., Knowles, C. and Nget Y.-L. (2010) The effect of irrigation time, root morphology and dentine thickness on tooth surface strain when using 5\% sodium hypochlorite and 17\% EDTA. International Endodontic Journal, 43, 190-199. doi:10.1111/j.1365-2591.2009.01655.x

[44] Baumgartner, J. and Mader, C. (1987) A scanning electron microscopic evaluation of four root canal irrigation regimens. Journal of Endodontics, 13, 147-157. doi:10.1016/S0099-2399(87)80132-2

[45] Pérez-Heredia, M., Ferrer-Luque, C.M., González-Rodríguez, M.P., Martín-Peinado, F.J. and González-Lópezet, S. (2008) Decalcifying effect of 15\% EDTA, 15\% citric acid, $5 \%$ phosphoric acid and $2.5 \%$ sodium hypochlorite on root canal dentine. International Endodontic Journal, 41, 418-423. doi:10.1111/j.1365-2591.2007.01371.x

[46] Faruk, H. (2003) Efficacy of various concentrations of citric acid at different $\mathrm{pH}$ values for smear layer removal. Oral Surgery, Oral Medicine, Oral Pathology, 96, 340344.

[47] González, L.S., Camejo, A.D., Sanchez, S.P. and Bolaños, C.V. (2006) Effect of CHX on the decalcifying effect of $10 \%$ citric acid, $20 \%$ citric acid, or $17 \%$ EDTA. Journal of Endodontics, 32, 781-784. doi:10.1016/j.joen.2006.02.006

[48] Mohamed, F.A. (2001) Effects of rotary instrumentation and different etchants on removal of smear layer on human dentin. The Journal of Prosthetic Dentistry, 85, 6772. doi:10.1067/mpr.2001.112792

[49] Ballal, N.V., Kandian, S., Mala, K. and Seetharama Bha, K. (2009) Comparison of the efficacy of maleic acid and ethylenediaminetetraacetic acid in smear layer removal from instrumented human root canal: A scanning electron microscopic study. Journal of Endodontics, 35, 15731576. doi:10.1016/j.joen.2009.07.021

[50] De-Deus, G., Souza, E.M., Marins, J.R., Reis, C., Paciornik S. and Zehnder, M. (2011) Smear layer dissolution by peracetic acid of low concentration. International Endodontic Journal, 44, 485-490. doi:10.1111/j.1365-2591.2010.01847.x 
[51] Şen, B.H., Wesselink, P.R. and Türkün, M. (1995) The smear layer: A phenomenon in root canal therapy. International Endodontic Journal, 28, 141-148. doi:10.1111/j.1365-2591.1995.tb00289.x

[52] Zhang, K., Kim, Y.K., Cadenaro, M., Bryan, Th.E., et al. (2010) Effects of different exposure times and concentrations of sodium hypochlorite/ethylenediaminetetraacetic acid on the structural integrity of mineralized dentin. Journal of Endodontics, 36, 105-109. doi:10.1016/j.joen.2009.10.020
[53] Seidberg, B. and Schilder, H. (1974) An evaluation of EDTA in endodontics. Oral Surgery, Oral Medicine and Oral Pathology, 4, 609-620. doi:10.1016/0030-4220(74)90294-1

[54] Cunningham, W.T., Martin, H. and Forrest, W.R. (1982) Evaluation of root canal débridement by the endosonic ultrasonic synergistic system. Oral Surgery, Oral Medicine, Oral Pathology, 53, 401-404. doi:10.1016/0030-4220(82)90442-X 